\title{
Macrophage migration inhibitory factor enhances lipopolysaccharide-induced fibroblast proliferation by inducing toll-like receptor 4
}

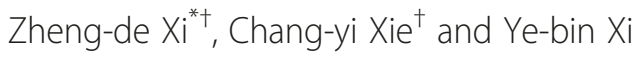

\begin{abstract}
Background: Fibroblast proliferation is a common manifestation of chronic inflammatory diseases, including rheumatoid arthritis (RA), Crohn's disease and ulcerative colitis, etc. To alleviate patient suffering, the mechanism underlying fibroblast proliferation should be elucidated.

Methods: CCK-8 assay was used to assess the stimulatory effect of LPS and macrophage migration inhibitory factor (MIF) on fibroblast proliferation. Then, TLR4 expression on fibroblast cell membrane was carried out by confocal scanning microscopy. Finally, real-time fluorescent quantitative PCR and flow cytometry were applied to determine the expression of TLR4 after MIF challenge.

Results: LPS alone directly stimulated the fibroblast proliferation. In addition, MIF showed co-stimulatory effect on LPS-induced fibroblast proliferation. Interestingly, fibroblast overtly expressed TLR4 without stimulation. After MIF stimulation, real-time PCR showed TLR4 mRNA levels were increased by about $33 \%$ in the fibroblasts; in agreement, TLR4 expression on the fibroblast membrane was increased by about $20 \%$, as shown by flow cytometry.

Conclusions: These findings indicated MIF elevates TLR4 expression in fibroblast, enhancing LPS-induced cell proliferation.

Keywords: Macrophage migration inhibitory factor, Toll-like receptor 4, Lipopolysaccharide, L-929 cell line, Connective tissue-derived fibroblast, Cell proliferation, Escherichia coli
\end{abstract}

\section{Background}

Rheumatoid arthritis (RA) and Crohn's disease are common chronic inflammatory diseases. Clinically, RA can cause joint swelling, pain, damage, and even disability; meanwhile, patients suffering from Crohn's disease usually present with symptoms like constipation, abdominal pain and diarrhea. Both diseases differ in etiology and pathogenic manifestations, but a similar clinical manifestation, with the fibroblast proliferation, playing an important role in both ailments. Therefore, exploring the

* Correspondence: xizhengde@sjtu.edu.cn

${ }^{\dagger}$ Equal contributors

Shanghai Institute of Immunology, Department of Immunology and Microbiology, Shanghai Jiao Tong University School of Medicine, Room 905 Building 5, 280 South Shanghai Chongqing Road, Shanghai 200025, China mechanism underlying fibroblast proliferation is of great significance.

In a previous study assessing prostaglandin E2 (PGE2) secretion by fibroblasts challenged by lipopolysaccharide (LPS) and macrophage migration inhibitory factor (MIF), we fortuitously found LPS alone stimulates fibroblast proliferation, with MIF playing a co-stimulatory role in enhancing LPS-induced cell proliferation, However, the underlying mechanism is not fully understood. Recent research has reported LPS induces lung fibroblast proliferation through TLR4 signaling[1-4]; in addition, the innate immune response can be regulated by MIF through modulation of Toll-like receptor 4 (TLR4) in macrophage[5]. This study aimed to elucidate the biological function of LPS and MIF in fibroblast proliferation. We propose here that MIF induced TLR4, an LPS receptor, 
boosting LPS-induced fibroblast proliferation (see Fig. 1). This hypothesis may possibly depict the involvement of MIF in LPS-induced fibroblast proliferation, which leads to synovial hyperplasia (RA) as well as intestinal lumen fibrosis and stenosis (Crohn's disease).

\section{Schematic diagram depicting MIF and LPS effects on fibroblast proliferation}

In order to unveil the mechanism of the co-stimulatory effect of MIF on LPS-induced fibroblast proliferation, the following hypothesis was proposed (Fig. 1).

LPS induced fibroblast proliferation via TLR4, and MIF enhanced TLR4 expression. Together, MIF has costimulatory function to enhance LPS-induced fibroblast proliferation via Toll-like receptor 4 induction. Blank and solid stars indicated naturally expressed and MIFinduced TLR4, respectively.

\section{Methods}

\section{Cell line and reagents}

The mouse connective tissue-derived fibroblast cell line L929 was obtained from Shanghai Fu Xiang Biotechnology Co., Ltd. (China). HyClone fetal bovine serum (FBS) was purchased from Shanghai Yu Bo Biological Technology Co., Ltd. (China). LPS (derived from E. coli O111:B4), CCK-8 (cell counting kit-8), 4 \% paraformaldehyde, sealing medium and trypsin were purchased from Beyotime Institute of Biotechnology Co., Ltd. (China); MIF was obtained from R \& D systems (USA); rabbit anti-mouse TLR4

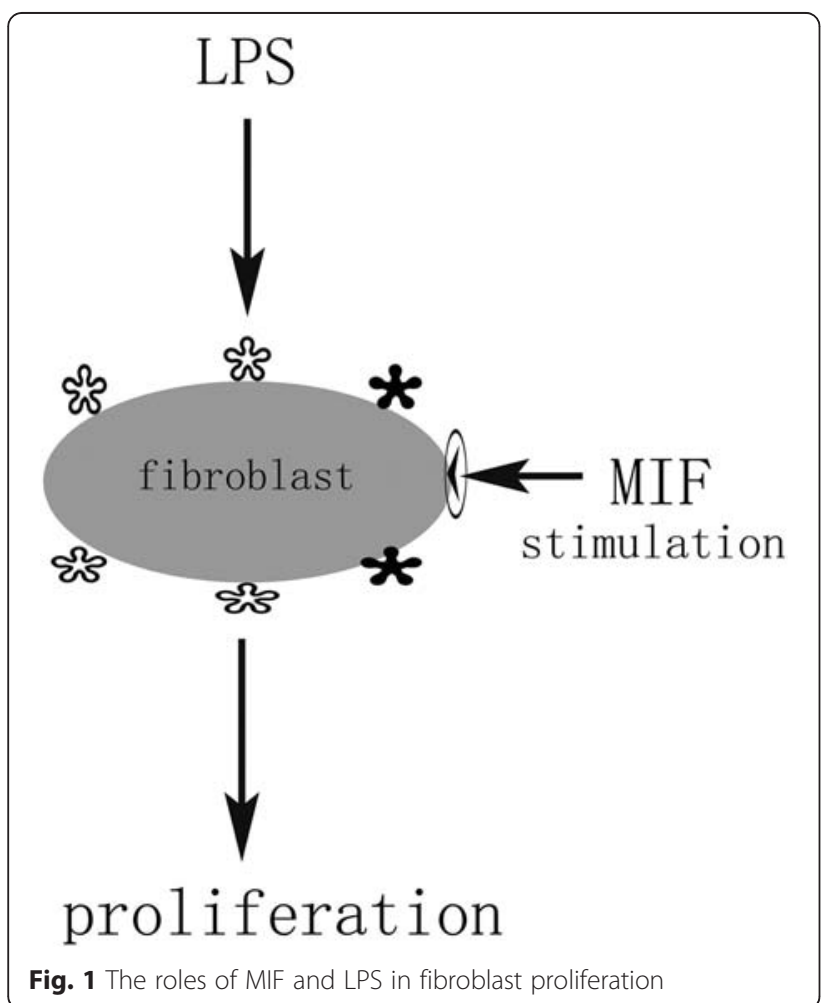

antibody, FITC-conjugated donkey anti-rabbit IgG secondary antibody and donkey serum were purchased from Santa Cruz Biotechnology, Inc. (USA). Quantitative PCR kit was purchased from Wuhan Google Biotechnology Co,. Ltd. (China). PE-conjugated anti-mouse TLR4/MD2 antibody (Miltenyi Biotec, Inc.) was purchased from Shanghai Univ-bio Co., Ltd. (China).

\section{CCK-8 assay for fibroblast proliferation assessment}

L-929 cells were cultured with DMEM containing $10 \%$ FBS, $100 \mathrm{U} / \mathrm{ml}$ penicillin and $100 \mu \mathrm{g} / \mathrm{ml}$ streptomycin at $37{ }^{\circ} \mathrm{C}$ in a humidified atmosphere with $5 \% \mathrm{CO}_{2}$ (Forma Series II CO2 incubator, Thermo Electron Co.). Mouse fibroblast suspension was adjusted to $5 \times 10^{4} / \mathrm{ml}$, and $200 \mu \mathrm{l}$ were seeded per well in 96-well plates. After $1 \mathrm{~h}$ incubation (to allow cells to adhere to plates), cells were treated with LPS at various concentrations for $48 \mathrm{~h}$. Then, cell proliferation was assesses by adding $20 \mu \mathrm{l}$ CCK- 8 reagent in each well, followed by incubation at $37{ }^{\circ} \mathrm{C}$ for $2 \mathrm{~h}$. Signals were spectrophotometrically measured at $450 \mathrm{~nm}$ on a full wavelength microplate analyzer (Molecular Device); data were recorded as optical density (OD). The procedure described above was also used to evaluate the effects of various concentrations of MIF in the presence or absence of $25 \mu \mathrm{g}$ LPS.

\section{Immunofluorescence for TLR4 detection}

A total of $1 \times 10^{6}$ L-929 cells were seeded on sterile coverslips (0.13 mm thickness) in each 6-well plates, in $1.5 \mathrm{ml}$ of medium. $40 \mathrm{~h}$ later, coverslips were gently washed 3 times with PBS and fixed with $4 \%$ paraformaldehyde at room temperature for $20 \mathrm{~min}$. After PBS wash, blocking was carried out with donkey serum $(1: 10)$ for $2 \mathrm{~h}$ at $37^{\circ} \mathrm{C}$; then, the coverslips were sequentially incubated with rabbit anti-mouse TLR4 antibody (1:50 dilution; $4{ }^{\circ} \mathrm{C}$ overnight) and FITC-conjugated donkey anti-rabbit IgG secondary antibody $\left(1: 100 ; 37^{\circ} \mathrm{C} 1 \mathrm{~h}\right)$. The coverslips were mounted with sealing medium, followed by analysis on a laser confocal scanning microscope (Zeiss LSM-710).

\section{Real time PCR for TLR4 mRNA expression quantitation}

L-929 cells were seeded $5 \times 10^{5}$ per well in 6-well plate treated with MIF at three concentrations, and two replicates per concentration were applied. $48 \mathrm{~h}$ later, the medium in each well was aspirated, the attached cells were washed with PBS; after addition of $1 \mathrm{ml}$ Trizopure, total RNA was extracted. RNA purity and concentration were assessed by OD measurement at $260 / 280 \mathrm{~nm}$ on spectrophotometer (Thermo Nanodrop 2000). cDNA was obtained with reverse transcription kit (ReverTra Ace-alpha), and real time PCR was carried out with Toyobo thunderbird SYBR qPCR Mix (quantitative PCR amplification kit). Specific primers were designed and synthesized by Invitrogen Biotechnology (China): TLR4 
[NCBI(GenBank):NM_021297], forward, 5'- AGTTTAG AGAATCTCTGGTGGCTGTG-3', and reverse, 5'- TTC CCTGAAAGGCTTGGTCT-3'); $\beta$-actin [NCBI(GenBank):NM_007393.3], forward, 5'- CTGAGAGGGAA ATCGTGCGT-3', and reverse, 5'-CCACAGGATTCC ATACCCAAGA-3'. Thermal cycling conditions included: initial denaturing step at $95^{\circ} \mathrm{C}$ for $1 \mathrm{~min} ; 40$ cycles of $95^{\circ} \mathrm{C}$ for $15 \mathrm{~s}, 58{ }^{\circ} \mathrm{C}$ for $20 \mathrm{~s}$ and $72{ }^{\circ} \mathrm{C}$ for $20 \mathrm{~s}$; final extension at $72{ }^{\circ} \mathrm{C}$ for $5 \mathrm{~min}$. All samples were tested in triplicate on 96 well PCR plate. Relative expression of the TLR4 gene was calculated using the $\triangle \triangle \mathrm{Ct}$ method.

\section{Flow cytometry for detection TLR4 expression on cell membrane}

L-929 cells were seeded at a density of $5 \times 10^{5}$ per well in 6-well plate, with MIF added at $375 \mathrm{ng} / \mathrm{ml}$ for $48 \mathrm{~h}$. Then, cells were pelleted centrifugation at $300 \times \mathrm{g}$ for $10 \mathrm{~min}$, and resuspended in $100 \mu \mathrm{l}$ buffer solution. Afterwards, $10 \mu \mathrm{l}$ PE-conjugated TLR4-MD2 (CD284) antibody was added for $10 \mathrm{~min}$ at $4{ }^{\circ} \mathrm{C}$, and cells were analyzed on flow cytometer (BD Accuri C6).

\section{Statistical analysis}

Statistical analyses were performed with SPSS software (SPSS 19, Inc, Chicago, IL, USA). Data are mean \pm SEM, and one-way ANOVA with dunnett's test was used for group comparisons. ${ }^{*} \mathrm{P}<0.05$ was considered statistically significant.

\section{Results}

\section{LPS induces mouse fibroblast proliferation}

After LPS $48 \mathrm{~h}$ of incubation, OD450 value were significantly higher in the two LPS-treated groups (5 and $25 \mu \mathrm{g} / \mathrm{ml})$ compared with control group $(\mathrm{P}<0.05)$, indicating that LPS induced cell proliferation in mouse fibroblasts. Importantly, cell proliferation was induced by LPS in a dose-dependent manner (Fig. 2).

\section{TLR4 is expressed in mouse fibroblast}

TLR4 expression in the macrophages is downregulated by MIF depletion, leading to the hypo-response of macrophage to LPS[5]. To assess the regulatory role of MIF in fibroblast TLR4 expression, we first examined the expression profile of TLR4 in the mouse fibroblast cell line L929. Under a confocal microscope, no FITC signal was observed, although clear cell outline was present (Fig. 3, left panel); meanwhile, a spindle-shaped fibroblast outline was high-lighted by FITC signal. The overt staining of cellular membrane suggested that TLR4 was widely expressed and uniformly distributed on the cellular membrane of mouse fibroblasts (Fig. 3).

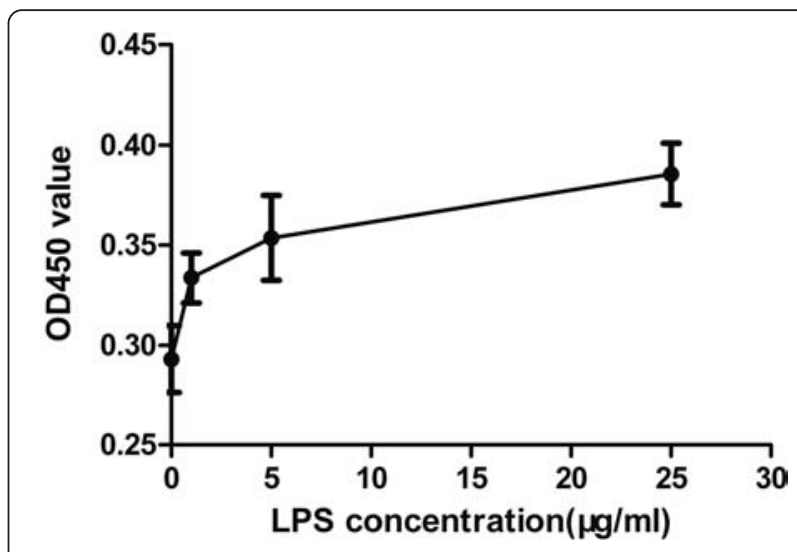

Fig. 2 LPS induces proliferation of fibroblast in a dose-dependent manner. Mouse fibroblasts were seeded in 96-well plate. 1 g, 5 g, $25 \mathrm{~g} / \mathrm{ml}$ LPS were added to various wells; control untreated cells were setup. 48 h later, 20 I CCK-8 reagent was added into each well for another 2 h. OD450 value was measured to assess cell number. One-way ANOVA with Dunnett's test was used to estimate the differences between the LPS-treated and control groups. The two LPS-treated groups(dot 3 and dot 4)showed more cells with the control group (dot 1). ${ }^{*} \mathrm{P}<0.05$

\section{MIF enhances TLR4 expression in fibroblast}

Mouse fibroblast cells were stimulated by MIF at $375 \mathrm{ng} /$ $\mathrm{ml}$. Real-time fluorescence quantitative PCR showed that TLR4 mRNA levels were increased by about $33 \%$. This was further confirmed by flow cytometry, which showed about $20 \%$ increase in TLR4 fluorescence signals after treatment with $375 \mathrm{ng} / \mathrm{ml}$ MIF in comparison with control cells (Fig. 4).

\section{MIF co-stimulates fibroblast proliferation}

After treatment with $25 \mu \mathrm{g} / \mathrm{ml} \mathrm{LPS}$, fibroblast proliferation was induced. Meanwhile, MIF could boost LPSinduced fibroblast proliferation. Interestingly, fibroblast cell proliferation increased with MIF dose. These data

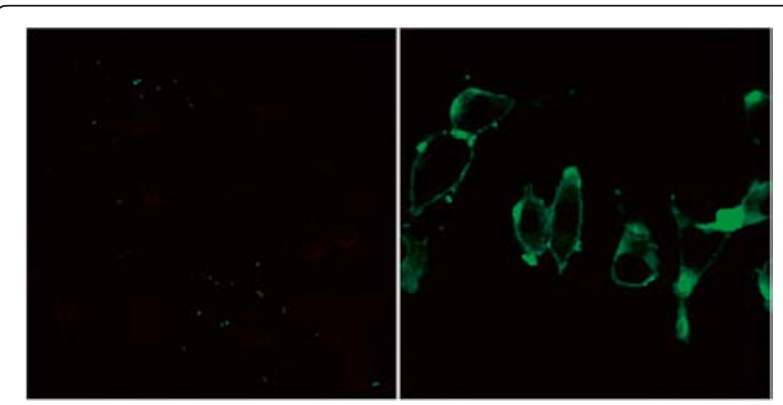

Fig. 3 Natural expression of TLR4 in fibroblast. Cells were observed by confocal microscopy. Left image shows the negative control (rabbit anti-mouse TLR4 antibody was not added), with no cell stained by FITC, and cell outline only dimly seen. Right image shows spindle-shaped fibroblasts, with cell membrane staining showing that TLR4 was widely expressed and uniformly distributed on cell membrane. Magnification: $\times 560$ 


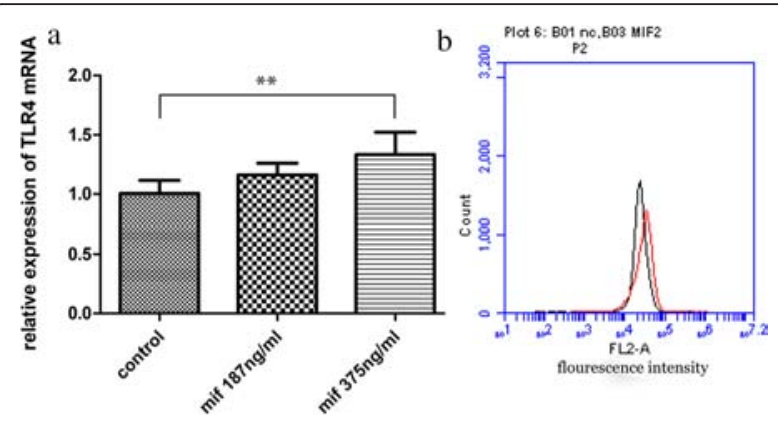

Fig. 4 Increased TLR4 expression by fibroblast after MIF stimulation. a Mouse fibroblast cells were stimulated with two different concentrations of MIF for $48 \mathrm{~h}$. Transcription levels of the TLR4 gene in mouse fibroblasts were up-regulated by about $33 \%$ after treatment with MIF at $375 \mathrm{ng} / \mathrm{ml}$. ${ }^{* * P}<0.01$ (b) The above finding was further verified by flow cytometry. All cells were stained by PE dye, and $375 \mathrm{ng} / \mathrm{ml}$ MIF-treated samples showed clear curve shift to the right of the PE-signal (red peak vs black peak); $20 \%$ elevation of TLR4 in fibroblast cells was observed. Data are representative of 3 independent experiments

indicated that LPS alone directly induced fibroblast proliferation, which was further enhanced by MIF. At the concentrations used in these experiments, MIF had no direct stimulating effect on fibroblast proliferation. The stimulatory effect of MIF on fibroblast proliferation was dependent on LPS. These findings strongly support our hypothesis (Fig. 5).

\section{Discussion}

Forty years ago, MIF was firstly proposed by Bloom BR in a study assessing delayed hypersensitivity[6]. It is considered the first cytokine found in human, and is nick-named as IL-0 by some researchers. Because of its capacity to inhibit macrophage migration, it was termed "MIF" (macrophage migration inhibitory factor). It is

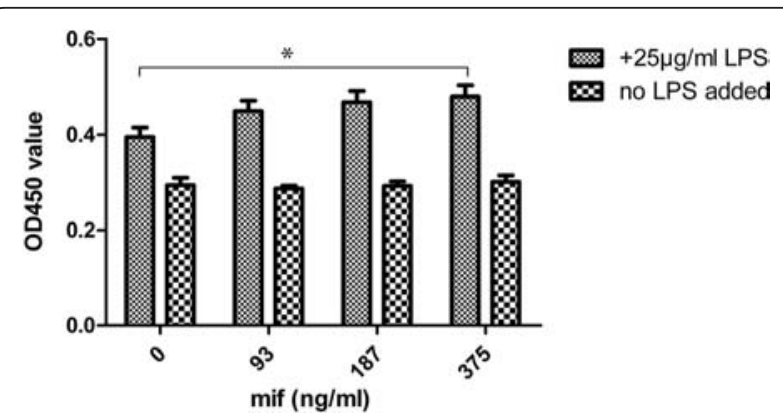

Fig. 5 Co-stimulatory effect of MIF on LPS-induced fibroblast proliferation. LPS was used at $25 \mathrm{~g} / \mathrm{ml}$, alongside several MIF concentrations, including $375 \mathrm{ng} / \mathrm{ml}, 187 \mathrm{ng} / \mathrm{ml}$ and $93 \mathrm{ng} / \mathrm{ml}$. In presence of LPS, OD450 value increased with MIF dose, which indicated MIF could co-stimulate fibroblast proliferation. Without LPS, MIF could not stimulate fibroblast proliferation within the dose range tested. This indicated that stimulatory effect of MIF on fibroblast proliferation was indirect, requiring LPS now known to be widely expressed in various cell types, including activated $\mathrm{T}$ cells, macrophages and anterior pituitary gland cells, etc.[7-10]. In addition to macrophage migration inhibition, other functions of MIF have yet to be fully elucidated.

Interestingly, Roger and colleagues reported that MIFdeficient macrophages have reduced TLR4 expression and are hypo-responsive in inducing TNF- $\alpha$ upon LPS and Gram-negative bacteria challenges[5]. These data indicate that MIF is essential for TLR4 expression in macrophages.

Multiple reports have demonstrated that LPS participates in a variety of diseases. For instance, LPS promotes cell proliferation in cultured human small intestinal lamina propria fibroblasts [11], human periodontal ligament fibroblasts [12] and adventitial fibroblasts [13], and each of which might induce corresponding diseases.

Both IL-1R and TLR are homologous in the intracellular adaptor molecule domain known as TIR (Toll-IL-1 receptor) domain $[14,15]$. IL-1 $\beta$ induces fibroblast proliferation, as evidenced by many experiments [16-18]. Because of the similarity of the cellular domain, we hypothesized that, combined with its agonist LPS, TLR4 can induce the fibroblast proliferation; indeed, $\mathrm{He} \mathrm{Z}$ and colleagues reported that LPS induces mouse lung fibroblast proliferation through TLR4 signaling[1]. Our results confirm that LPS stimulates the proliferation of fibroblast L-929, in a dosedependent fashion (Fig. 2).

Macrophages and fibroblasts can be regarded as basic cells in synovium, with synovial fibroblasts overtly outnumbering macrophages. We hypothesize that fibroblast may also express TLR4, with MIF upregulating TLR4, which contributes to fibroblast proliferation in presence of LPS. As shown above, TLR4 was detected in mouse fibroblast cell line L-929 by laser confocal scanning microscopy. As expected, TLR4 was widely distributed on the cellular membrane (Fig. 3). MIF induced TLR4 expression in fibroblast was also demonstrated by real-time PCR assay, and further confirmed by flow cytometry (Fig. 4). Taken together, MIF, as an internal factor, induces TLR4 expression in fibroblast; this may enhance LPS-induced fibroblast proliferation.

Synovial hyperplasia is an important clinical manifestation of RA, and the underlying mechanism is far to be elucidated. It can be caused by viruses, mycoplasma and chlamydia, but the role of bacterial components has been occasionally reported. Indeed, LPS is an important external factor involved in arthritis occurrence [19-25]. We speculate that LPS may originate from mouth, gut, urogenital tract and respiratory tract in RA patients. Then, bacterial pathogen-produced LPS migrate into the joints through blood circulation, inducing cytokine release and fibroblast proliferation. 


\section{Conclusions}

Our data clearly indicate MIF increases TLR4 expression in fibroblast, enhancing the LPS-induced cell proliferation. These findings further describe the roles of LPS and MIF in fibroblast proliferation. Further studies should focus on determining how MIF induces TLR4, exploring the related signal transduction pathway. Blockage of LPS-TLR4 and MIF-CD74 signaling may be promising in treating synovial hyperplasia in RA.

\section{Availability of supporting data} None.

\section{Requesting deposition of data}

None.

\section{Abbreviations}

ANOVA: Analysis of variance; CCK-8: cell counting kit-8; DMEM: Dulbecco's Modified Eagle Medium; LPS: lipopolysaccharide; MIF: macrophage migration inhibitory factor; qPCR: quantitative polymerase chain reaction; RA: rheumatoid arthritis; TIR: Toll-IL-1 receptor; TLR4: Toll-like receptor 4.

\section{Competing interests}

The authors declare that they have no competing interests.

\section{Authors' contributions}

Z Xi - conception and design of study, analysis and interpretation of data, writing the manuscript. C Xie -design of cell culture, confocal microscopy assay, flow cytometry, and CCK-8 assay, acquisition of data, interpretation of data, and statistical analysis. Y Xi - design of ELISA and real-time PCR assay, acquisition of data, interpretation of data. All authors have read and approved the final manuscript.

\section{Acknowledgements}

This work was supported by the Science and Technology Commission of Shanghai Municipality Foundation (No. 11ZR1431700)

Received: 19 June 2015 Accepted: 19 January 2016 (P)

\section{References}

1. He Z, Gao Y, Deng Y, Li W, Chen Y, Xing S, et al. Lipopolysaccharide induces lung fibroblast proliferation through Toll-like receptor 4 signaling and the phosphoinositide3-kinase-Akt pathway. PLoS One. 2012;7(4):e35926.

2. He Z, Deng Y, Li W, Chen Y, Xing S, Zhao X, et al. Overexpression of PTEN suppresses lipopolysaccharide-induced lung fibroblast proliferation, differentiation and collagen secretion through inhibition of the PI3-K-AktGSK3beta pathway. Cell Biosci. 2014;4(2):2.

3. He Z, Zhu $Y$, Jiang $H$. Inhibiting toll-like receptor 4 signaling ameliorates pulmonary fibrosis during acute lung injury induced by lipopolysaccharide: an experimental study. Respir Res. 2009;10:126.

4. Yang H, Kaneko M, He C, Hughes MA, Cherry GW. Effect of a lipopolysaccharide from E. coli on the proliferation of fibroblasts and keratinocytes in vitro. Phytother Res. 2002;16(1):43-7.

5. Roger T, David J, Glauser MP, Calandra T. MIF regulates innate immune responses through modulation of Toll-like receptor 4. Nature. 2001;414(6866):920-4.

6. Bloom BR, Bennett B. Mechanism of a reaction in vitro associated with delayed-type hypersensitivity. Science. 1966;153(3731):80-2.

7. Hirose S, Ooki S, Higuchi M, Osawa T. Macrophage migration inhibitory factor (MIF) produced by a human T cell hybridoma clone. Microbiol Immunol. 1991;35(3):235-45.

8. Calandra T, Bernhagen J, Mitchell RA, Bucala R. The macrophage is an important and previously unrecognized source of macrophage migration inhibitory factor. J Exp Med. 1994;179(6):1895-902.

9. Nishino T, Bernhagen J, Shiiki H, Calandra T, Dohi K, Bucala R. Localization of macrophage migration inhibitory factor (MIF) to secretory granules within the corticotrophic and thyrotrophic cells of the pituitary gland. Mol Med. 1995;1(7):781-8.

10. Chuang YC, Chen HR, Yeh TM. Pathogenic roles of macrophage migration inhibitory factor during dengue virus infection. Mediators Inflamm. 2015;2015:547094

11. Chakravortty D, Kumar KS. Induction of cell proliferation and collagen synthesis in human small intestinal lamina propria fibroblasts by lipopolysaccharide: possible involvement of nitric oxide. Biochem Biophys Res Commun. 1997;240(2):458-63.

12. Takemura A, Matsuda N, Kimura S, Fujiwara T, Nakagawa I, Hamada S. Porphyromonas gingivalis lipopolysaccharide modulates the responsiveness of human periodontal ligament fibroblasts to platelet-derived growth factor J Periodontal Res. 1998:33(7):400-7.

13. Xiao-jun C, Min F, Liang C, Li L, Yuan-yuan R, Xiao-bo H, et al. Expression and role of adiponectin receptor 1 in lipopolysaccharide-induced proliferation of cultured rat adventitial fibroblasts. Cell Biol Int. 2010;34(2):163-9.

14. Boraschi D, Tagliabue A. The IL-1 receptor family. Semin Immunol. 2013; 25(6):394-407.

15. Li X, Jiang S, Tapping RI. Toll-like receptor signaling in cell proliferation and survival. Cytokine. 2010;49(1):1-9.

16. Lertchirakarn V, Birner R, Messer HH. Effects of interleukin-1 beta on human pulpal fibroblast proliferation and collagen synthesis. J Endod. 1998;24(6):409-13.

17. Lee WS, Lim JH, Sung MS, Lee EG, Oh YJ, Yoo WH. Ethyl acetate fraction from Angelica sinensis inhibits IL-1 $\beta$-induced rheumatoid synovial fibroblast proliferation and COX-2, PGE2, and MMPs production. Biol Res. 2014;47(1):41.

18. Lee EG, Lee SI, Chae HJ, Park SJ, Lee YC, Yoo WH. Adrenomedullin inhibits IL-1 $\beta$-induced rheumatoid synovial fibroblast proliferation and MMPS, COX-2 and PGE2 production. Inflammation. 2011;34(5):335-43.

19. Yoshino S, Sasatomi E, Ohsawa M. Bacterial Lipopolysaccharide acts as an adjuvant to induce autoimmune arthritis in mice. Immunology. 2000;99(4):607-14

20. Yoshino S, Ohsawa M. The role of lipopolysaccharide injected systemically in the reactivation of collagen-induced arthritis in mice. Br J Pharmacol. 2000;129(7):1309-14.

21. Takahashi K, Kato Y, Sugiyama T, Koide N, Kawai M, Fukada M, et al. Production of murine collagen-induced arthritis using Klebsiella pneumoniae $\mathrm{O} 3$ lipopolysaccharide as a potent immunological adjuvant. Microbiol Immunol. 1999;43(8):795-801.

22. Yoshino S, Sasatomi E, Mori Y, Sagai M. Oral administration of lipopolysaccharide exacerbates collagen-induced arthritis in mice. J Immunol. 1999;163(6):3417-22.

23. Terato K, Ye XJ, Miyahara H, Cremer MA, Griffiths MM. Induction by chronic autoimmune arthritis in DBA/1 mice by oral administration of type II collagen and Escherichia coli lipopolysaccharide. Br J Rheumatol. 1996;35(9):828-38.

24. Noyori K, Okamoto R, Takagi T, Hyodo A, Suzuki K, Koshino T. Experimental induction of arthritis in rats immunized with Escherichia coli 0:14 lipopolysaccharide. J Rheumatol. 1994;21(3):484-8.

25. Goldenberg DL, Reed JI, Rice PA. Arthritis in rabbits induced by killed Neisseria gonorrhoeae and gonococcal lipopolysaccharide. J Rheumatol. 1984;11(1):3-8.

Submit your next manuscript to BioMed Central and we will help you at every step:

- We accept pre-submission inquiries

- Our selector tool helps you to find the most relevant journal

- We provide round the clock customer support

- Convenient online submission

- Thorough peer review

- Inclusion in PubMed and all major indexing services

- Maximum visibility for your research

Submit your manuscript at www.biomedcentral.com/submit 